\title{
Family business foundations: theoretical and empirical investigation
}

\author{
Carmela Elita Schillaci ${ }^{1}$, Marco Romano ${ }^{1 *}$ and Melita Nicotra ${ }^{2}$
}

\author{
* Correspondence: \\ romanom@unict.it \\ 'Dipartmento di Economia e Impresa, \\ Università degli Studi di Catania, \\ Palazzo delle Scienze, C.so Italia, \\ 55 CATANIA - 9511, Italy \\ Full list of author information is \\ available at the end of the article
}

\begin{abstract}
The paper examines family business foundations as connectors between the firm and the family from which they originate, adopting a coevolution approach that considers family and business as two subsystems which coevolve in creating a different species, the family business. Foundations are seen as coevolution facilitators supporting the coevolution process, outlining a specific grow path for family firms, and ensuring family business sustainability. An empirical analysis on Italian family business foundations is developed. The Italian context is taken into consideration because family firms are the backbone of the Italian economy, and the largest family foundations are those created by the most important entrepreneurial families. Data bring to light the structural role played by family business foundations in Italy and their involvement in the field of culture and art, research and training, health care, and territorial responsibility. The analysis shows the growth of family business foundations in recent years and their connection with long-lived companies with whom a close connection is maintained, leading to a lasting intergenerational sustainability.

Keywords: Family business; Foundations; Coevolution process; Sustainability
\end{abstract}

\section{Background}

The pace of growth of foundations linked to family businesses leads to the investigation of the extent of the phenomenon to understand their distinctive characteristics and the prospects for value creation. The present contribution explores the way family firms assure their longevity, feed their sustainability, and improve their reputational assets through family foundations.

The object of analysis are foundations that originate from a family business, here called family business foundations, not much explored by researchers and here analyzed as tools for the continuity and persistence of the family firm over time. It is a well-defined set of organizations deriving from the intersection between the set of corporate foundations and that of family foundations.

With corporate foundations, we refer to organizational models addressed at improving the effectiveness and impact of the philanthropic activities of firms that are not necessarily 'family firms'. With family foundation, we refer to foundations born from the desire of acquiring 'high net worth individual' (HNWI) status, i.e., people with high net worth not necessarily resulting from the activity of a family business.

Corporate foundations and family foundations have been partially explored (Bodo and Monteverdi 2009); however, there are no empirical studies on family business

C 2013 Schillaci et al.; licensee Springer. This is an Open Access article distributed under the terms of the Creative Commons Attribution License (http://creativecommons.org/licenses/by/2.0), which permits unrestricted use, distribution, and reproduction in any medium, provided the original work is properly cited. 
foundations involving simultaneous and mutual observations of the two 'bodies': business and family. Family business foundations are investigated here not as isolated subjects but as connectors between the company and the family from which they originate.

The Italian context is taken into account because of particular characteristics family foundations assume in this country: family firms are the backbone of the Italian economy, and the largest family foundations in Italy are those created by the most important entrepreneurial families. From a theoretical point of view, a coevolution approach as a new perspective to study the role of family foundations in dealing with family firms is adopted. Coevolution implies the mutual evolutionary influence between two species independent of each other. Each species exerts a selective pressure on the other, so they evolve together (Van den Bergh and Stagl 2004).

Adopting this approach, which is not unusual in social science, allows us to consider family and business as two subsystems which coevolve, creating a different species, the family business. The longtime persistence of the family business species is the result of a successful coevolution path of both family and business organizations (Schillaci 2008).

In this process, the two subsystems have to face the coevolution paradox that is derived from the opposition between the family's natural attitude to closeness and persistence and the business's needs for strategic changing and openness. In this context, family foundations assume the role of coevolution facilitator, the right organizational solution to support the coevolution process and to outline a specific growth path for family firms. With increasing degrees of intensity, they are proposed as 'trust centers' for a family-business-environment relationship.

The real essence of foundations coincides with the ability to ensure the family business' sustainability, including, in a more structured dimension, the themes of generation transition and of capital asset maintenance in time. The need of the family to ensure 'continuity', to leave a mark, and to go beyond its limits, beyond the physical perimeter, and beyond space-time dimensions becomes feasible through the foundation.

A physiological coevolution leads towards forms of persistence: the family exceeds the self-protective instincts of emotional ties, wins over time, and protects itself by ensuring the survival of the dynasty as well as the firm, which benefits from the impact of a stable family and of its values, intensifying its strategic and competitive dimensions.

The data set for empirical analysis contains a broad sample of Italian family business foundations. It is a sample drawn from a number of different listings and then explored through information available from family foundations' websites.

The research mainly includes foundations whose model, governance, and assets reveal that the family has a predominant role in their creation and in the definition of their strategies and missions. Basing on such data, the role of family business foundations in facing the coevolution paradox and in assuring family firm continuity is shown.

Theory

The concept of intergenerational family sustainability

One of the natural human needs is to ensure its own continuity. The desire to persist over time, beyond the physical life, is one of the strongest push that directs human actions and choices. The urge of ambition and the innate aspiration to leave a mark, to go beyond limits, even beyond the physical space-time perimeters, drives us to design 'great works' to shape the future beyond the predictable. 
Family business makes possible the idea of perpetuating the founder's name and actions over time. It permits, if well managed, to preserve and amplify assets accumulated in life, entrusting the economic potential associated with the business entity to future generations.

Family businesses are the engines of both industrialized countries and developing economies. They contribute to the socioeconomic development. impact on the entrepreneurial drive, and represent major employment opportunities. Above all, family businesses represent 'life projects', vigorous centers that combine entrepreneurial skills and activities with typical traits of the family as a community of values and strong relationships.

The crisis, which erupted in the USA that soon became global, has established the vulnerability of the economic and monetary systems as interconnected and characterized by the inability/failure to adopt appropriate models of governance. Today, there is a need for economic development models based on the valorizations of people and of the social and civilian dimensions of communities. The contraction of the welfare state and of some forms of state intervention reinforces solidarity concerns and tensions.

The new response patterns, no longer related only to market economies or vertical and authoritarian approaches, bring out the importance of solidarity and selforganization models (Stiglitz et al. 2010). A new conscious capitalism is an emerging philosophy, directed to pursuing ethical behaviors (Virtue Ethics). Family capitalism related to the job, to the firm, and to the territory has always brought into question the aims of purely economic and utilitarian models and their perverse effects.

Indeed, the family's hard work, as an organic community where 'you think and toil, you suffer and rejoice in the work and you live side by side, face to face, family to family, street by street' (Sapelli 2010), has always been a subject of conscious and human capitalism, based on a participatory approach without nepotism and exclusion, emphasizing trust and not fear, construction and optimism, and rejecting prejudices and inertia.

The natural and innate idea of family businesses to persist beyond the founders, in a continuity of values and intergenerational wealth, is based on a concept of 'sustainable family'. The search for new market models emphasizes approaches based on cooperation and enhances emotional investments, the sense of belonging, and the social and economic continuity over time.

Family business sustainability is the ability to ensure the persistence of the family over time, combining the continuity of the family myth with social responsibility and creating a community of values and intentions. The theme of longevity or persistence of the family is one of the main topics on which to focus the theoretical and empirical contributions on the family business.

In a survey of the 100 oldest family businesses in the world, Italian family businesses are positioned among the top places (O'Hara 2004). The oldest family business is the Japanese 'Kongo Gumi' founded in 578, at second place is the Japanese 'Hoshi Ryokan' founded in 718, third is the French 'Château de Goulaine' founded in 1000, and at fourth place is the Italian Fonderia Pontificia Marinelli founded in 1000.

The reflection on the degree of longevity is very exciting because the ability of a family business model to persist over time is the result of coevolutionary path of two complex systems: on the one hand, the growth and development of the company, and on 
the other, the growth/stability of the family (Schillaci 2008). With the exception of monarchical-imperial dynasty, the economy is the only way through which the family ensures their survival over time (Kets De Vies et al. 2007).

The company grows over time and adapts strategically to changes, thereby ensuring the permanence of the family and the heirs in a delicate and fragile chemistry between change and maintenance, opening and closing, and innovation and tradition. Ensuring family longevity means managing the apparent contradictions that characterize family businesses that are forced to maintain a symbiotic relationship between two organisms: 'family' and 'enterprise', with different paths, instances, and purposes but dialectically related.

The meaning of family business sustainability, apart from dealing with the well-known themes of the new generation passage and the capacity of maintaining the economic and financial assets over time, introduces a more articulated dimension of analysis. Family sustainability is directed to the construction of the family/business binomial and the ability to act beyond the boundaries of the firm, maintaining and enhancing the living traditions of productive territories and communities.

To invest in 'sustainability' means for the family firm to believe not only in the importance of adopting an ethical and accountable model open to the community but also the importance of enhancing the return in terms of 'trust' and 'reputation' generating reciprocity and cooperation.

Through significant investments in the sustainability dimension, it contributes to the creation of a 'myth', keeping alive and celebrating the sacredness of the family in the name of the founder and of his/her values. The myth of the family becomes part of the community's oral tradition and gets stakeholders emotionally involved by giving an aura of respect and deference to the creative activity of the founder and his/her descendants.

From the need of preserving accumulated wealth in life, it goes to acquiring a collective security and shared heritage of the family, in a broader sense of wealth, which means being with the community, building opportunities and pathways, and rooting and hardening relations between the business and the social context.

\section{Family capitalism in Italy}

Researches on family firms have emphasized the importance of family capitalism as an efficient organization solution of economic activities even in the later stages of the industrialization process (Colli 2006). The spread of the family ownership and control in Europe, USA, Asia, in developing countries, and in smaller nations contradicts the conventional wisdom according to which family businesses are not able to support economic growth in high-capital intensity areas.

Family business was considered a proprietary solution typical of start-up and early stages, and it was usually related to labor-intensive production processes and craft markets marked by strong regionalism. However, history has shown that family dynasties continue to play a significant role in big industrial groups and in all economic sectors, such as in the case of financial services, not previously considered suitable to the family formula.

The presence of the family provides the maintenance of values such as trust, commitment, and relational continuity of management and corporate reputation (Ferda 2010). 
The relevance of family capitalism and modernity, both for SME and for big companies, is well documented.

It is estimated that family businesses contribute from $70 \%$ to $90 \%$ of the global GDP per year (Family Firm Institute 2012). In Europe, the most recent data indicate that family businesses account for over $60 \%$ of European companies (European Commission 2009).

In Italy, $73 \%$ of companies are family controlled and employ more than half of the national workforce (Family Firm Institute 2012). These are companies with a long tradition: Italy has the largest number of members of the association Henokiens (family firms more than 200 years old that are still largely managed and owned by the founding family).

The Italian family businesses are mostly small, but medium and large sizes family firms also exist. The Osservatorio AUB (2010) shows that 57.1\% of companies with a turnover exceeding 50 million Euros are family controlled and generates $41.1 \%$ of the total revenues produced by medium and large firms of the country. They also represent the class of companies that more than others has ensured employment in the last 3 years, with an increase in the total number of employees to $+12.1 \%$ compared to the results of cooperatives and consortia $(+3 \%)$, coalitions $(+2 \%)$, multinational companies $(-4.2 \%)$, state companies $(-10 \%)$, and above all the companies controlled by a private equity $(-14.3 \%)$. This confirms the central role of family firms of medium to large sizes in terms of employment with about 2.5 million employees.

With reference to the structures of governance and control mechanisms, in Italy, the family's involvement in business is particularly significant. The ownership of the family is almost always high. The model of governance is direct, with a concentration of strategic, operational decisions and control. The management, if outside the family, is generally in-house trained and close to the family (Pozza et al. 2008).

The ownership structure is generally a hierarchical group, with operating companies linked to the holding company. Besides the possibility to exploit the leverage to hold shareholder control, the hierarchical group structure has allowed a relative separation between the family and the business, resolving conflicts in the family holding company and leaving economic problems in the operating subsidiaries.

The cumbersome presence of the family has been identified as a dominant feature in the Italian business and has been defined as 'amoral' in sociological terms (Banfield 2006; Alesina and Ichino 2009). In economic activities, it has historically been a cause of inefficiency and has lead to a low degree of internationalization and a low presence of management.

Apart from the sociological schema of things, family capitalism in Italy has a singularity than in other countries: the prevalence of family leadership even among larger companies. According to data of the Family Business Network (www.fbn-i.org), the governance of family firms allows the full control of the family business unlike those in other countries, such as Germany, France, Holland, and Sweden, where there is a smaller presence in the family ownership structure. This peculiarity appears to be a distinctive feature of Italian capitalism, something that persists over time, well beyond the initial stages of the growth process. In general, for its influence, dissemination, and organization, family capitalism in Italy is structurally destined to persist, and there are several historical reasons that confirm this idea. 
Among others, a significant role has been played by the gradual reduction of the state's direct presence in the economy, which has reinforced many family-controlled groups. The numerous privatizations undertaken during the 1990s have allowed family businesses (for example, the Benetton, Del Vecchio, De Agostini, and Riva families) to expand their size and incorporate parts of the ex public conglomerate.

The morphology of the financial system has considerably influenced the growth rate of the family model. In Italy, the relationship between family business and financial system has been intimate and heavily regulated by factors such as individual and family reputation.

The strength of ties among local banks, their officials, and the local businesses have supported the expansion and development processes of family firms, defining local financial models. Moreover, the growth paths of firms have rarely considered opening forms of risk capital. The lack of development of the stock market, combined with a weak legal framework for the protection of minority shareholders, has further contributed to maintain the family concentration.

The economic history of the country has unequivocally confirmed the widespread of family capitalism as a socioeconomic model capable of ensuring growth, employment, and investment. The structural characteristics of Italy have validated, over time, the sustainability of this model, which represents the heart of the Italian industrial structure.

The Italian company is a family business, a family capitalism that has emerged in terms of competitive ability for differentiation, customization, internationalization, development, and reticular local district but which continues to be marked by an excess of family members' protectionism, non-managerial governance, financial constraints, and intergenerational drift.

The excellence of family capitalism made in Italy has been a prize catch by foreign investors, often in search of attractive investment to steer their huge portfolios. The global crisis has prompted deep reflections on the need of redesigning the features of a renewed model of family capitalism and has also made clear the difficulties of the welfare state in Italy.

In Italy, rethinking of capitalism especially in light of the emergence of new social demands means reflecting on the developmental model of family businesses. The theme of the family is a public fact, a crucial issue on the agenda of the country.

Family businesses are an integral part of the plot of the industrial system, and their defense and reorientation are a competitive advantage for the entire nation, an industrial heritage of experience and values that can build the recovery. The natural and innate idea of family businesses to persist beyond the founder, in an intergenerational continuity of values and wealth, coincides with the new priorities and hierarchies of values. Family businesses coherently combine business activities and attitude towards the creation of 'community of values and intentions'.

Sustainability is a family affair; companies such as multigenerational family business are naturally and spontaneously addressed to favor the agenda of sustainable development in all its ramifications. Post-modern family values are emerging based not only on the continuity of history and myth of the family but also on the ability of the family business to open to the community and territories and to maintain such participation over time across generations. 
Today, the most dynamic part of Italian capitalism is based on the presence of family businesses, which in most cases are at the third or the fourth generation, which have demonstrated virtuous links between family proprietary forms and competitive capabilities. Italy is characterized by multigenerational continuity, solid reputation in the business, participatory skills, and local interest: Italian family firms have all the typical features that are emerging around the world in the 'life after capitalism'.

\section{Italian foundations for family and business sustainability: a coevolution framework}

Family businesses are tied to the Italian territory: the value of bonds, the sense of mutual responsibility, trust, and a common vision of future construction; family firms have made a pact with the territory, even outside the district boundaries where decades before the pact was born.

In this dimension of moral economy, the family business as a life project becomes the instrument for community sustainability and participation. Post-modern family businesses see in the 'foundations' a form of organization to ensure their persistence and at the same time to create a virtuous path. Foundations represent extraordinary historical and cultural innovations of our time. Foundations enhance the characteristics of typical Italian family capitalism, in terms of long-term customer relationships, local knowledge development, and networking creation.

Our argument is directed to state that the protection and enhancement of Italian family capitalism, the backbone of the national economic system, are linked to foundations as organic communities able to develop the social and strategic potential of family businesses. Family business foundations are increasingly becoming the strategic space to ensure the persistence of the family over time and to identify a route to build their own myth and their virtuous growth. The study of family foundations and the reasons behind their creation can provide a significant understanding of the phenomenon of longevity and evolution of family businesses.

In the rest of the world, especially in Anglo-Saxon countries, the use of the instrument, foundation, is already well codified. In leading economies, foundations represent an important tool for the protection of assets and wealth and for implementing forms of philanthropy and social engagement. In Italy, family business foundations are characterized by the affirmation of social responsibility strategies and collective sharing.

The intergenerational continuity of the family business is based on the ability of the company/family to impact beyond their boundaries, valuing the traditions of territories and the processes of social construction. The ideal place to accommodate the process of coevolution and to power the myth of the family can be represented by the family foundations. Family foundations, with increasing degrees of intensity are proposed as trust centers to ensure the relationships between the family and its environment, as active instruments to support family business reputation. The foundation as a form of metagovernance dispossesses the traditional family business from a centralized model and serves as a mediator with respect to the multitude of actors inside and outside the firm.

Beyond the strategic trajectories and paths, the essence of foundations coincided with the ability to ensure the family business' sustainability, including, in a more structured way, the theme of the generation passage and the maintenance of capital assets in time. Adopting the coevolutionary perspective, foundations can fulfill the task of trust centers through which the family business subsystems coevolve (Schillaci 2008). 
The coevolution perspective is derived from ecological and biological studies that consider changes in the genetic composition of one species (or group) in response to a genetic change in another (Van den Bergh and Stagl 2004; Mitleton-Kelly and Papaefthimiou 2002). More generally, it is the idea of some reciprocal evolutionary changes in interacting species. The term is usually attributed to Ehrlich and Raven's study of butterflies on plants (Ehrlich and Raven 1964).

The coevolution implies the mutual evolutionary influence between two species independent of each other. Each involved species exerts selective pressure on the other, so they evolve together. At first glance, it seems that everything is involved in coevolution. This assumption might stem from the fact that virtually all organisms interact with each other and presumably influence their evolution in some way. But coevolution should not be invoked without reasonable evidence that the traits in each species are a result of or have evolved from the interaction between the two species.

There are different modes through which species interact producing positive, negative, or neutral effects. Positive interactions in a community are broadly classified into four types: protocooperation, mutualism, commensalism, and scavenging.

In particular, protocooperation is a positive interspecific interaction in which both partners are mutually benefitted and increase the chance of their survival. Between the two organisms, there is a perfect morphological interaction which generates a new species, which is cataloged, classified, and analyzed as a different species.

The application of the evolution theories to social science is not unusual. The evolution was implicit in the early works on the emergence of the 'bureaucracy' (Weber 1978), in the coevolution and historic approach of Chandler on M-forms, in the studies on the impact of the environment on organizations (Weich 1979), in the ecologic theories of Aldrich, and in the contributions of Nelson and Winter (1982) and Levitt and March (1988) dealing with knowledge and learning capabilities. The adoption of the coevolution approach allows an original perspective for studying family business, contributing to build a specific theory on this object.

General theoretical frameworks have been used to explain the family business phenomenon, turning to the literature related to small business, life cycle theory, entrepreneurship and start-up, corporate governance, organizational change, strategic plan, and resources (Sharma 2006). Such studies are applicable to every kind of business, regardless of its family nature.

On the contrary, by assuming a coevolution perspective, the object and the focus of a specific theory on family business is evident. The specific object of the coevolution theory is the family business with a focus on the study of the relational dynamic and the interference process between the two systems, family and business (McCann et al. 2001). It permits the reconstruction of the symbiotic relations between two organisms under observation, the family and the business, and of the way such two subsystems coevolve, creating a different species, the family business.

Therefore, the longtime persistence of the species family business is the result of a successful coevolution path of both family and business organization. The comprehension of the family business nature is possible only through a simultaneous analysis. Traditional family business studies have mainly focused on the business, considering the family as a factor influenced or being influenced by the business. However, it is 
important to understand how the family and the business change and evolve to further understand how they together give origin to a different entity.

Between the family and the business, not only an institutional overlapping exists, as explained by influential analytical models in the past (e.g., Landsberg 1983), but they are morphologically integrated. Each is the mirror of the other (Habbershon et al. 2006). They change and coevolve together, in a protocooperation interaction. The coexistence of the two organisms, family and business, not only generates positive effects, but it is also possible that negative results emerge, as stressed by different studies on family business (Miller and Le Breton-Miller 2006).

Complexities in the succession process, difficulties in managerialization, conflicts between the business-involved family members and the not business-involved ones, and confusion between the family wealth and the family business assets are all issues investigated by various authors to underline the pathological relations between the two integrated systems. A protocooperation process and a mutually advantageous influence for the two organisms are realized when conditions able to harmonize centrifugal-centripetal forces and match concentration-heterogeneity dimensions are satisfied.

Family firms endure if they are able to manage symbiotic mechanisms facing the coevolution paradox. The coevolution paradox is derived from the opposition between the family's natural attitude to closeness and the business' strategic openness.

From a sociological and relational perspective, families are networks of strong, dense, stable, long-lasting, bidirectional, and multidirectional ties. Such networks are independent and not interested in the openness to and in the link with other networks. This is their weak characteristic (Granovetter 1983). Families tend to feed themselves and their members; even when they open themselves to other networks, they favor their members. On the contrary, businesses are addressed towards continuous openness processes with the environment and constant redefinitions of their business models and of the competences needed for a good performance. The specificity of the family business is embedded in its ability to manage the coevolution paradox by governing the family seeking protection and closeness, on the one hand; business needs for strategic changing and openness, on the other hand.

The degree of locked/unlocked in the governance structure is the fil rouge that is useful to value and mediates the decision-making process of family businesses over the time. Thus, the nature of such relationship is characterized by different levels of uncertainty and conflict, in both the family and business contexts. In particular, it regards the new entrant's acceptance and the unlocking process to the same family members, involving descendants, husband/wife, or others relatives in the business activities. Moreover, it is relevant when the unlocking process involves managerial experts present outside the family structure, employing managers or consultants to prominent company position. At the same time, middle and top managers who do not get involved in carrier progression of major positions in the company chart or are not admitted to the ownership structure may experience the same phenomenon of unlocking the organizational governance to external individuals. Also, such insight is related to the acceptance of independent board members or private equity representatives in the family business governance structure or boardroom. Ultimately, the degrees of locked/ unlocked could be analyzed from an external perspective, to spur in the 'Territoire' ethical value present in the family and the business. It involves directly the evolution of 
the concept of corporate social responsibility of family firms to contribute, statue, and consolidate a greater wealth creation in their local context (Zocchi 2005).

Therefore, foundations are useful organizational solutions to manage the coevolution paradox and to govern the family protective natural attitude and the business strategic openness. Foundations embody a vital and physiological set of relationships among family members, the protagonists of the company, and all the stakeholders.

Moreover, the foundation defends the family business and its assets from the family and incompetence of the heirs. Indeed, the trend towards protectionism and the spread of 'familism' could affect the persistence over time. Transitions on the roles of government attributed on the basis of dynastic affiliation and not on merit are among the main causes of dissolution of family assets and decline of the business.

The foundations are able to manage the contradictions that characterize families and businesses and to enhance the symbiotic relationship between the two organisms, to valorize different but dialectically coexisting pathways and targets.

The foundation, as an integral yet external part of the company, mitigates the mutually destructive forces sacralizing and keeping alive the good name of the family and ensuring the persistence of the assets over time. The foundation, as an entity outside the enterprise but idiosyncratically incorporated in the scope of the family wealth, has a dual nature (internal-external) and is proposed as a coevolutionary diaphragm, the center of confidence, to adjust the evolutionary race of the two subsystems.

The foundation extends over time the value produced by the founders beyond his/ her physical life over the life cycle of the same company, in an amplified space/time dimension; the family business evolves creating the conditions for its sustainability.

\section{Method}

Objects of analysis of the empirical investigation are foundations that originate from family businesses, here called family business foundations. It is a well-defined set of organizations deriving from the intersection between the set of corporate foundations and that of family foundations (Figure 1).

We refer corporate foundations as organizational models addressed at improving the effectiveness and impact of the philanthropic activities of firms that are not necessarily

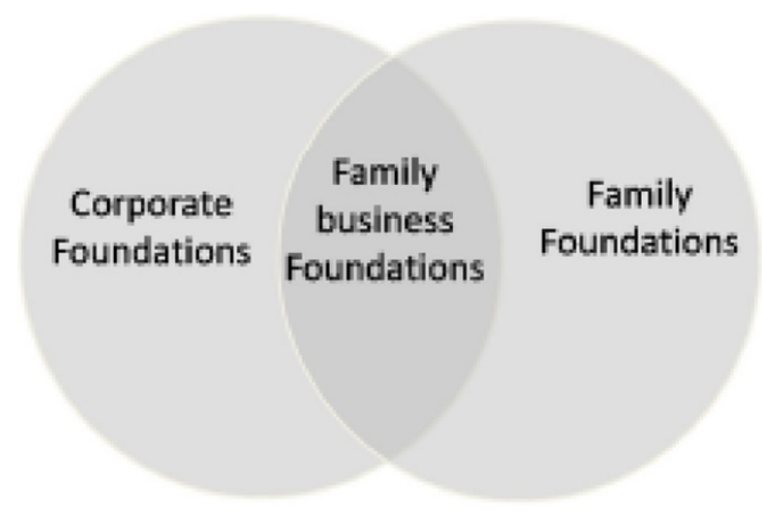

Figure 1 Family business foundation. 
'family firms'. We refer family foundations as foundations born from the desire of HNWI, i.e., people who have abundant wealth not necessarily resulting from the activity of a family business. Family business foundations are investigated not as isolated subjects but as connectors between the company and the family from which they originate.

A first component of investigation is the analysis of the field where they operate. Moreover, even industries where the related family business operates are explored.

Secondly, the foundations and family firms' dates of constitution are examined. The analysis shows that in the last decade, there has been an exponential increase in family business foundations created from the most long-lived enterprises, constituted in the first half of the twentieth century.

Finally, special attention is paid to the importance given by the family and the firm to the reputation and persistence of their name over time. In this direction, it is important to underline the correspondence between the name of the founder and the foundation name, between the foundation name and the company name, and the foundation name and the brand. The correlation between these categories is here taken into consideration as an index of the attachment of the family to their origins and the need felt by members to keep the memory alive through the transmission of the 'name' to future generations.

At the same time, the value assigned to the family business's reputation, value that is both the cause and effect of the foundation's creation, was derived from the database of the Italian association Centromarca, of the foundation Altagamma, and of the Italian Order of Merit for Labor.

The detection of family business foundations in Italy, as defined above, was launched from the list of the Italian family foundations (represented in Figure 1). These foundations, born from the desire of individuals who possess a vast family fortune not necessarily related to business activities, were gathered from the report of Pharoah (2009). Also, data on corporate foundations (represented in Figure 1) were obtained from the report of the Solidalitas Foundation.

For each foundation, a web search was subsequently performed in order to verify the nature of family business foundation and then to detect if the heritage is closely linked to a company still active on the national territory and if family controlled. The screening allowed us to discard those foundations resulting from non-family businesses and family foundations whose assets do not come from a family business. From 126 foundations, we were able to identify 16 . Since the lists of family foundations and corporate foundations from which we obtained data were incomplete, the data set was integrated by collecting data from Italian family businesses.

Information was also obtained by investigating on family businesses belonging to the Italian association Centromarca, the foundation Altagamma, and in which at least a member belongs to the Italian Order of Merit for Labor.

This choice is derived from the consideration that family businesses belonging to Centromarca, Altagamma, or to the Order of Merit for Labor presumably have invested in reputation and have used their financial and relational capital for the creation of a foundation.

The association Centromarca promotes the affirmation of the values of the Italian brand system in the market and in society. Founded in 1965, associated with about 200 


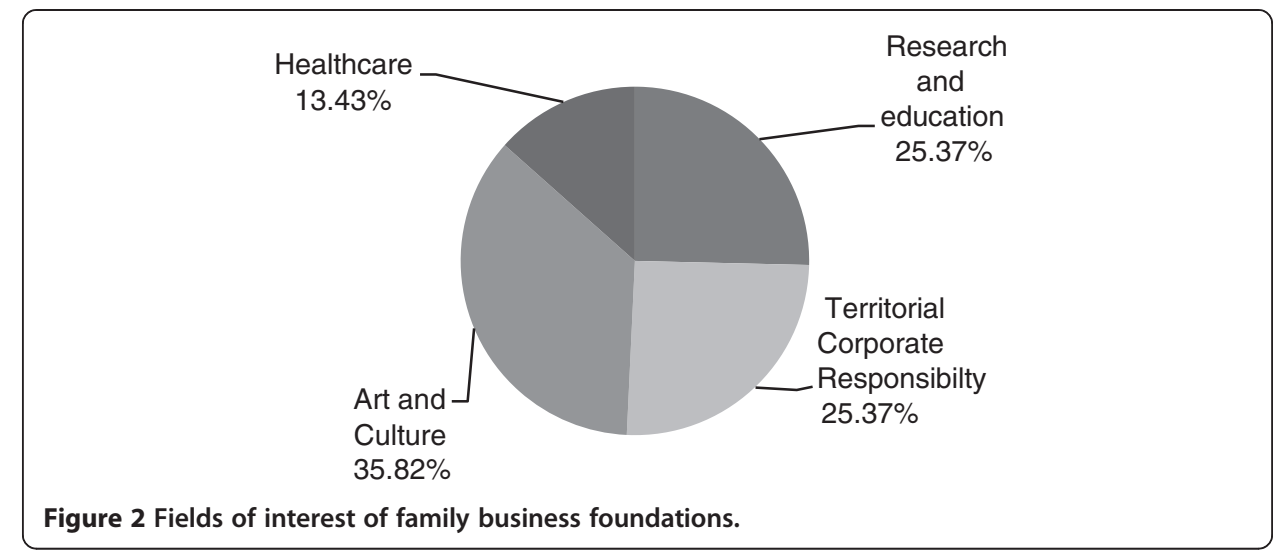

active enterprises in various sectors of consumer goods (food, chemical for the house and for the person, textile, electrical, DIY, toys, and home entertainment), it ensures their reputation, coordinates their collaboration with institutions, consumerist organizations, media, academia, and in general with all stakeholders.

The Altagamma Foundation, founded in 1992, brings together Italian companies whose brands are internationally famous. Its mission is to promote the Italian industrial excellence and culture, through the enhancement of companies' image, the development of effective business models, the activation of relationships with international trading partners, and the trademark protection.

The Italian Order of Merit for Labor is the institution that gathers entrepreneurs who have received public recognition because of their contribution to the creation of economic development in Italy. The Federation was founded in 1923. Today, the award is granted annually by the President of the Republic to 25 entrepreneurs who are distinguished in the fields of industry, agriculture, trade, tourism and services, crafts, credit, and insurance activities, with important implications particularly in society and employment.

Borrowing from the database of such associations, we have identified family businesses creating foundations. Following this method, 65 family business foundations have been identified. By integrating them with family business foundations previously

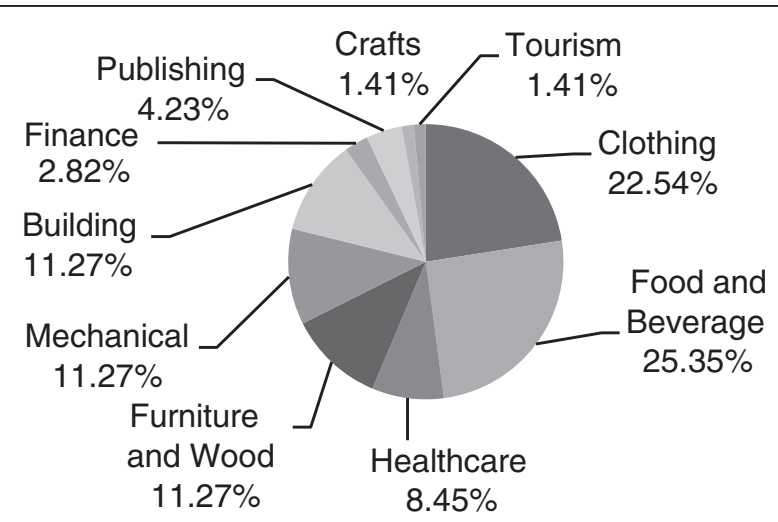

Figure 3 Family businesses' industries. 


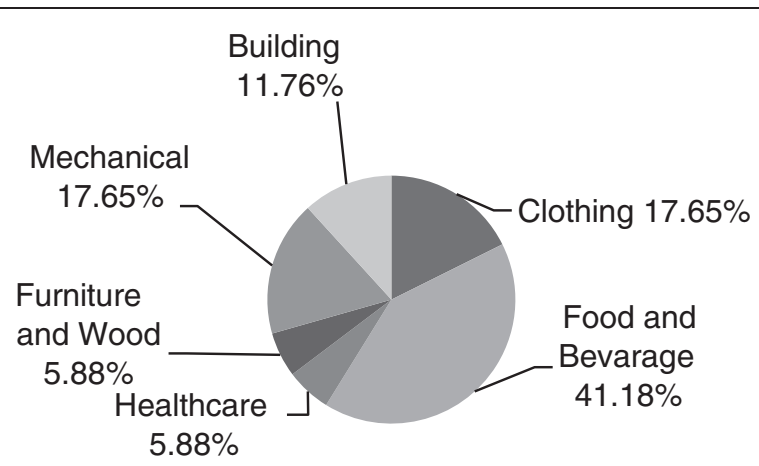

Figure 4 Family businesses' industries in relation to foundations operating in the field of research and education.

detected and cleaning the data set from duplicates, we have created a data set of 72 family business foundations.

\section{Results and discussion}

Fields of interest of family business foundations

The empirical analysis starts with the identification of the fields of interests of family business foundations, representing their mission, scopes, and philanthropic activities. The fields of interests have been distinguished into four classes:

- Research and education

- Territorial corporate responsibility

- Art and culture

- Health care

From the analysis of the purpose (Figure 2), we obtained a substantial homogeneity of the identified four classes. It should be noted that there was a greater interest for the sector 'Art and culture' which includes $35.82 \%$ of the foundations and a small percentage $(13.43 \%)$ for the category 'Health care'. In the two remaining categories 'Research and

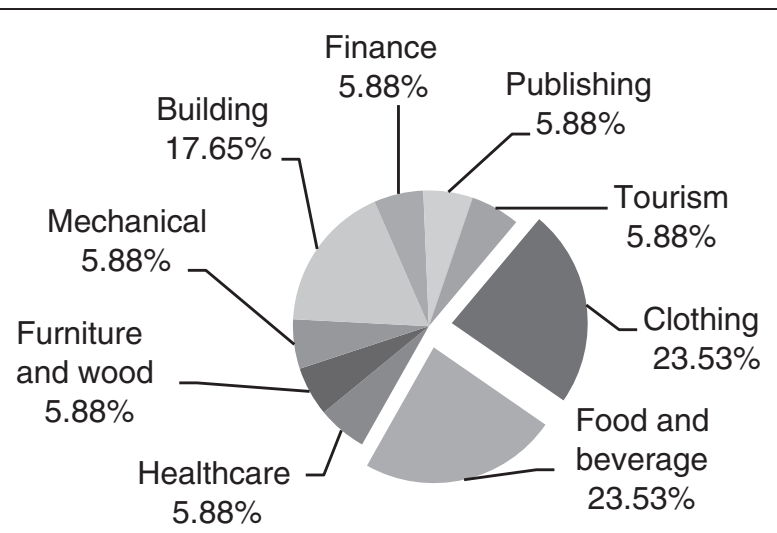

Figure 5 The family business sector in relation to foundations operating in the field of territorial social responsibility. 


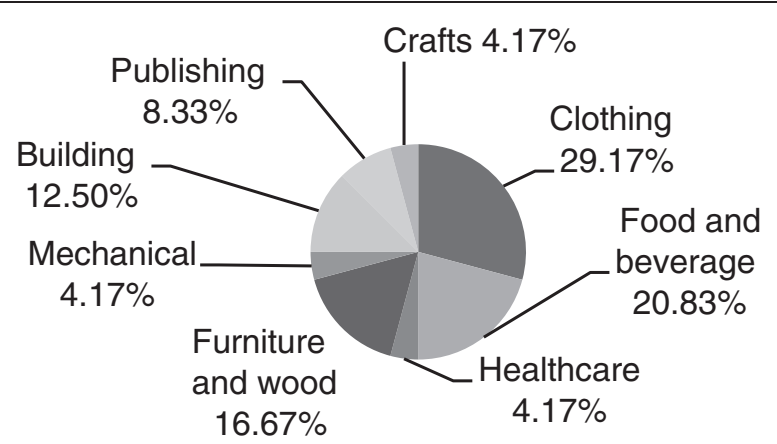

Figure 6 The family business sector in relation to foundations operating in the field of art and culture.

education' and 'Territorial corporate responsibility', the residual 50\% of the detected foundations is equally present.

Foundations are investigated here as entities strictly connected with the family businesses of origin. Hence, we need to detect even the sectors in which family businesses operate, which are grouped into ten classes:

- Clothing, textiles, fashion, accessories, and footwear

- Food and beverage

- Health care and pharmaceutical

- Furniture, wood

- Mechanical

- Building

- Finance

- Publishing

- Crafts

- Tourism

Approximately $50 \%$ of the analyzed family firms operates in the field 'Clothing textiles, fashion accessories, and footwear' (22.54\%) and in 'Food and beverage' (25.35\%), typical sectors of the tradition and excellence of the 'Made in Italy' (Figure 3).

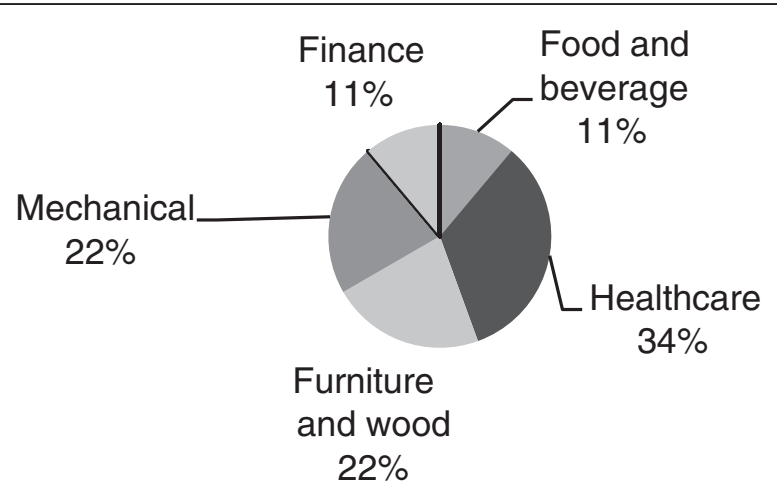

Figure 7 Family business sector in relation to foundations operating in the field of health care. 


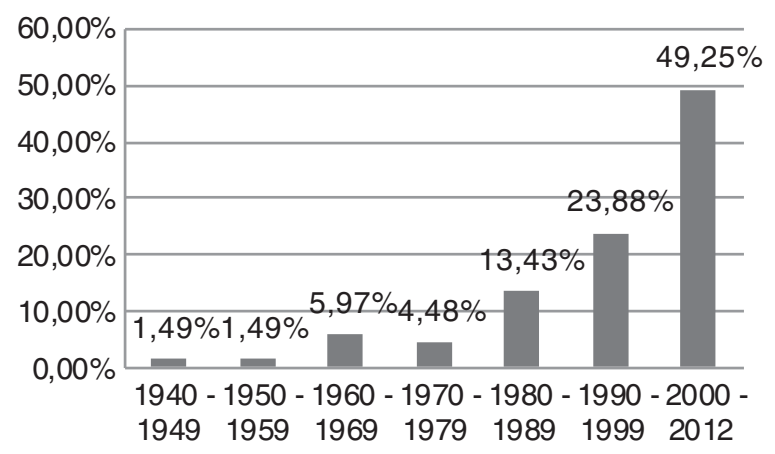

Figure 8 Year of constitution of family business foundations.

Crossing the data relating to family businesses' industries and the four classes in which the activities of the family business foundations are cataloged, we have verified the connection among them. Forty-one percent of the foundations performing their activities in the field of Research and education are connected to companies operating in the food and beverage industry (Figure 4) that prefer to invest in next-generation businesses, training, and developing human capital.

We can also notice a quite homogeneous distribution of the industries where family business related to foundations dealing with territorial corporate responsibility operate (Figure 5) with an endemic prevalence of the food and beverage and clothing industries. Figure 6 shows the distribution in the different sectors in which family firms related to the art and culture foundations operate. The importance of creating a foundation whose activity is connected to the sector of the related family business emerges in the health sector. In Figure 7, we can notice that foundations working in this area are mainly those linked to firms involved in the health care industry.

\section{Longevity of the family business foundations}

An analysis of foundations' dates of establishment has shown a growing interest of the Italian entrepreneurial families in the constitution of a foundation in the last decades. Since 1970, there has been an exponential increase in the birth of foundations under consideration (Figure 8).

By comparing the dates of establishment of the foundations and the activities they perform, we can notice an increasing interest for the sector art and culture, which represent $46.43 \%$ of foundations born since the year 2000 (Table 1).

The observation of the family businesses' dates of establishment shows the crucial role played by long-lived firms in contributing in a responsible manner to the

Table 1 Longevity of the family business foundations and area of intervention

\begin{tabular}{lccc}
\hline Fields & \multicolumn{3}{c}{ Longevity of the foundation (\%) } \\
\cline { 2 - 4 } & Before $\mathbf{1 9 8 1}$ & $\mathbf{1 9 8 1}$ to $\mathbf{2 0 0 0}$ & After 2000 \\
\hline Research and education & 22.22 & 27.59 & 25.00 \\
Territorial corporate responsibility & 33.33 & 27.59 & 17.86 \\
Art and culture & 22.22 & 31.03 & 46.43 \\
Health care & 22.22 & 13.79 & 10.71 \\
Total & 100 & 100 & 100 \\
\hline
\end{tabular}




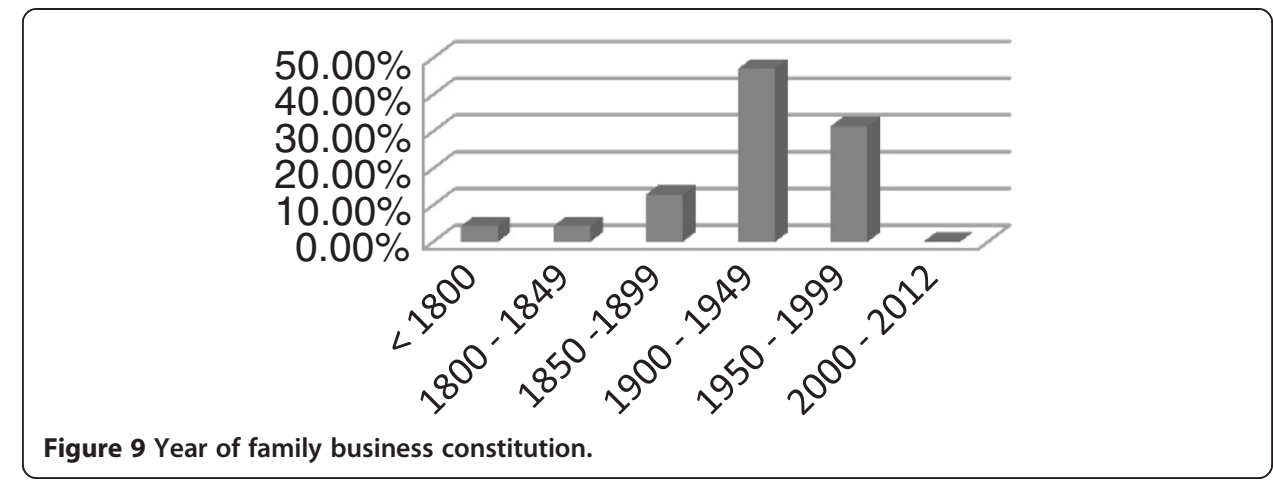

development of quality of life and territories, increasing at the same time their visibility and improving their reputation and relationships with stakeholders.

Figure 9 shows that $79 \%$ of foundations is connected to a company born in the twentieth century; in particular, $47.14 \%$ of enterprises linked to a foundation was founded on the first half of the twentieth century and $31.43 \%$ on the second half (Figure 9).

\section{The persistence of the family name}

The socially responsible behavior behind the creation of a foundation helps to strengthen the brand value of the company and to develop trust and brand loyalty and the name of the family business. The growth of reputation is a qualifying element of differentiation; it transforms threats into opportunities in an increasingly complex and dynamic competitive arena, improves the relationship with institutions and financial actors, and guarantees intergenerational sustainability. Hence, family firms need to give consistency to their reputational project to connect the family name with the brand and the foundation name, enhancing their responsible behavior. Such considerations lead us to detect if the reputational project of family firm is reliable, maintained, and enhanced.

In Table 2, we can see how many entrepreneurs replicate their name or the name of their families in the foundation name: the name of the foundation coincides with the family name in $82.86 \%$ of the cases; $67.14 \%$ of foundations shows a convergence not only between the name and the founder and the foundation name, but also with the name of the family business, and in $69.57 \%$ of cases, foundation name, family business name, and brand name coincide.

The importance of reputation for family business, and above all of brand reputation, is also detected from data provided by Centromarca, Altagamma Foundation, and the Italian Order of Merit for Labor. The $46.48 \%$ of the total number of companies analyzed is either a member of Centromarca or Altagamma. In particular, $23.94 \%$ is associated with

Table 2 Convergences of foundation name, founder name, family business name, and brand

\begin{tabular}{lc}
\hline Convergences & Percentage \\
\hline Foundation name $=$ founder name & 82.86 \\
Foundation name $=$ founder name $=$ family business name & 67.14 \\
Foundation name $=$ family business name & 71.83 \\
Foundation name $=$ brand & 71.01 \\
Foundation name $=$ family business name $=$ brand & 69.57 \\
\hline
\end{tabular}




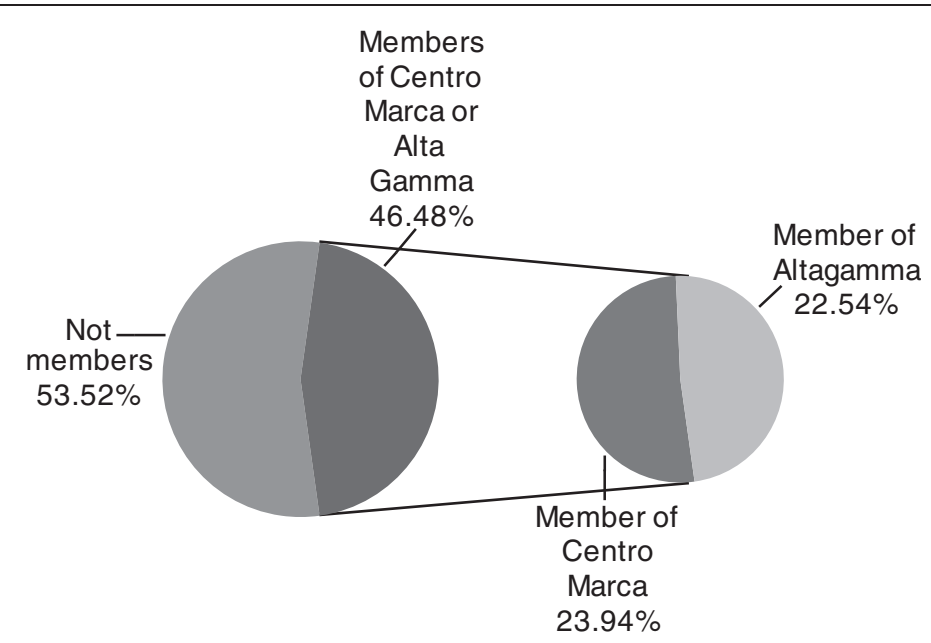

Figure 10 Centromarca and Altagamma foundation.

Centromarca and $22.54 \%$ with Altagamma Foundation. Only 3\%, represented by the two companies and Illy Caffè and Della Valle Group, belongs to both groups (Figure 10).

Many family businesses sponsoring foundations (71.83\% of foundations observed) have at least a member who belongs to the Italian Order of Merit for Labor. This is indicative of the fact that the analyzed family businesses have invested in quality and reputation. Looking at the dates of membership in the Italian Order of Merit for Labor and the foundation constitution, we can notice that among the $71.83 \%$ of the family businesses where at least a member belongs to the Italian Order of Merit for Labor, $57.14 \%$ created the foundation after the honor and $42.86 \%$ before it. In the first case, we can assume that the membership to the Italian Order of Merit for Labor has been a stimulus to the 'maintenance' of the reputation and the name of the family. In the second case, probably the creation of the foundation has contributed to the prestige of the family from which it is derived (Figure 11).

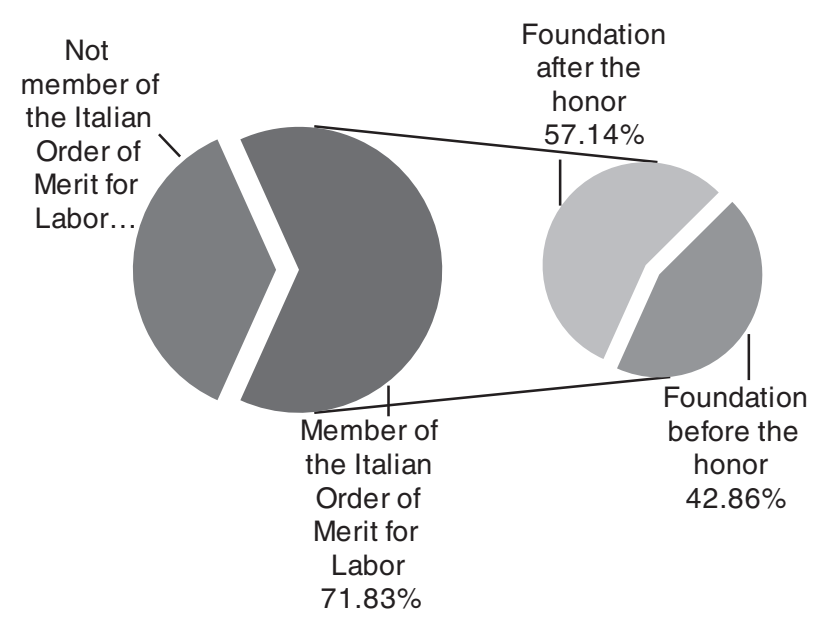

Figure 11 Italian order of merit for labor. 


\section{Conclusions}

The contribution investigates on family business foundations that are foundations originating from family businesses and owning characteristics both of corporate foundations and family foundations. Family business foundations are analyzed as connectors between the company and the family from which they originate, adopting a coevolution approach that considers family and business as two subsystems, which coevolve in creating a different species, the family business.

In this context, foundations are seen as coevolution facilitators supporting the coevolution process, outlining a specific grow path for family firms, and ensuring family business sustainability. The Italian context is taken into consideration. In Italy, family firms are the backbone of the economy, and the largest family foundations are those created by the most important entrepreneurial families.

Therefore, an empirical analysis on Italian family business foundations is developed. Data bring to light the structural role played by family business foundations in Italy, their involvement in the field of culture and art, research and training, health care, and territorial responsibility. The analysis shows the growth of family business foundations in recent years and their connection with long-lived companies with whom a close connection is maintained leading to a lasting intergenerational sustainability. Hence, they are candidates to become one of the most innovative, proactive, and constructive organizations in the modern economic scene.

Competing interests

The authors declare that they have no competing interests.

\section{Authors' contributions}

All author contributed equally to this work. All authors read and approved the final manuscript.

\section{Author details}

${ }^{1}$ Dipartmento di Economia e Impresa, Università degli Studi di Catania, Palazzo delle Scienze, C.so Italia, 55 CATANIA - 9511, Italy. ${ }^{2}$ Science and Technology Park of Sicily, Z.I. Blocco Palma I, Stradale Vincenzo Lancia 57, Catania 95121, Italy.

Received: 28 June 2013 Accepted: 15 August 2013

Published: 30 Dec 2013

\section{References}

Alesina, A, \& Ichino, A. (2009). L'ttalia fatta in casa. Milan: Mondadori.

Banfield, EC. (2006). Le basi morali di una società arretrata. Bologna: II Mulino.

Bodo, R, \& Monteverdi, A. (2009). Le corporate foundations in Italia. Milan: Rapporto di ricerca Solidalitas.

Colli, A. (2006). Capitalismo familiare. Bologna: II Mulino.

Ehrlich, PR, \& Raven, PH. (1964). Butterflies and plants: A study in co-evolution. Evolution, 1, 586-608.

European Commission. (2009). Overview family-business-relevant issues: research, network, policy measures and existing studies. Brussels: European Commission.

Family Firm Institute. (2012). Family Firm Institute, Inc. http://www.ffi.org/.

Ferda, E. (2010). Family business reputation: A literature review and some research questions. Electronic Journal of Family Business Studies (EJFBS), 4, 133-146.

Granovetter, M. (1983). The strength of weak ties: A network theory revisited. Sociological Theory, 1, 201-233.

Habbershon, TG, Williams, M, \& MacMillan, JC. (2006). A unified systems perspective of family firm performance. In PZ Poutziouris, KX Smyrnios, \& SB Klein (Eds.), Handbook of research on family business (pp. 451-465). Cheltenham, UK: Edward Elgar.

Kets De Vies, M, Carlock, RS, \& Florent-Treacy, E. (2007). Family business on the couch: A psychological perspective. San Francisco: John Wiley \& Sons.

Landsberg, IS. (1983). Managing human resources in family firms: The problem of institutional overlap. Organizational Dynamics, 12(1), 39-46.

Levitt, B, \& March, JG. (1988). Organizational learning. Annual Review of Sociology, 14, 319-340.

McCann, JE, Leon-Guerrero, AY, \& Haley, JD. (2001). Strategic goals and practices of innovative family business. Journal of Small Business Management, 39(1), 50-59.

Miller, D, \& Le Breton-Miller, I. (2006). Family governance and firm performance: Agency, stewardship, and capabilities. Family Business Review, 19(1), 73-87. 
Mitleton-Kelly, E, \& Papaefthimiou, MC. (2002). Co-evolution of diverse elements interacting within a social ecosystem. In P Henderson (Ed.), Systems engineering for business process change. Springer. ISBN 1852333995.

Nelson, RR, \& Winter, SG. (1982). An evolutionary theory of economic change. Cambridge: Belknap Press/Harvard University Press.

O'Hara, WT. (2004). Centuries of success: lessons from the world's most enduring family businesses. Avon, Massachusetts: Adams Media Corporation.

Osservatorio AUB. (2010). Osservatorio Aidaf-Unicredit-Bocconi su tutte le aziende familiari italiane di medie e grandi dimensioni.

Pharoah, C. (2009). Family foundations philanthropy in UK, Germany, Italy, US. London: Alliance Publishing Trust.

Pozza, L, Prencipe, A, \& Markarian, G. (2008). Earnings management in family firms: evidence from R\&D cost capitalization in Italy. Family Business Review, 3, 71-88.

Sapelli, G. (2010). La nobile fragilità dell'imprenditore che non tradisce i suoi uomini. Corriere della sera.

Schillaci, CE. (2008). Famiglia, impresa e paradosso coevolutivo. Una diversa prospettiva d'indagine sul family business. In C De Vecchi \& G Fraquelli (Eds.), Dinamiche di sviluppo e internazionalizzazione del family business (pp. 420-442). Bologna: II Mulino.

Sharma, P. (2006). An overview of the field of family business studies: current status and directions for the future. In PZ Poutziouris, KX Smyrnios, \& SB Klein (Eds.), Handbook of research on family business (pp. 196-214). Cheltenham, UK: Edward Elgar.

Stiglitz, J, Sen, A, \& Fitoussi, JP (2010). La misura sbagliata delle nostre vite. Perché il PIL non basta più per valutare benessere e progresso sociale. Milan: Etas Kompass.

Van den Bergh, CJM, \& Stagl, S. (2004). Coevolution of economic behaviour and institutions: Towards a theory of institutional change. Journal of Evolutionary Economics, 13(3), 289-317.

Weber, M. (1978). Economy and society. Berkeley: University of California Press.

Weich, KE. (1979). The social psychology of organizing. Reading, MA: Addison-Wesley.

Zocchi, W. (2005). Le imprese familiari di fronte alla responsabilità sociale, working paper presentato al convegno "La responsabilità sociale delle imprese del Piemonte Orientale nel contesto del processo di internazionalizzazione e globalizzazione dei mercati". Università del Piemonte Orientale. Novembre.

$10.1186 / 2192-5372-2-22$

Cite this article as: Schillaci et al: Family business foundations: theoretical and empirical investigation. Journal of Innovation and Entrepreneurship 2013, 2:22

\section{Submit your manuscript to a SpringerOpen ${ }^{\circ}$ journal and benefit from:}

- Convenient online submission

- Rigorous peer review

- Immediate publication on acceptance

- Open access: articles freely available online

- High visibility within the field

- Retaining the copyright to your article

Submit your next manuscript at $\boldsymbol{~ s p r i n g e r o p e n . c o m ~}$ 